\title{
IL-34 and M-CSF share the receptor Fms but are not identical in biological activity and signal activation
}

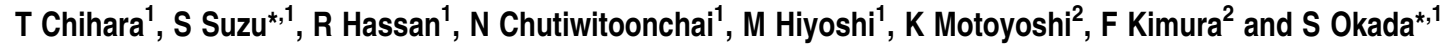

Macrophage colony-stimulating factor (M-CSF) regulates the production, survival and function of macrophages through Fms, the receptor tyrosine kinase. Recently, interleukin-34 (IL-34), which shares no sequence homology with M-CSF, was identified as an alternative Fms ligand. Here, we provide the first evidence that these ligands indeed resemble but are not necessarily identical in biological activity and signal activation. In culture systems tested, IL-34 and M-CSF showed an equivalent ability to support cell growth or survival. However, they were different in the ability to induce the production of chemokines such as MCP-1 and eotaxin-2 in primary macrophages, the morphological change in TF-1-fms cells and the migration of J774A.1 cells. Importantly, IL-34 induced a stronger but transient tyrosine phosphorylation of Fms and downstream molecules, and rapidly downregulated Fms. Even in the comparison of active domains, these ligands showed no sequence homology including the position of cysteines. Interestingly, an anti-Fms monoclonal antibody (Mab) blocked both IL-34-Fms and M-CSF-Fms binding, but another MAb blocked only M-CSF-Fms binding. These results suggested that IL-34 and M-CSF differed in their structure and Fms domains that they bound, which caused different bioactivities and signal activation kinetics/strength. Our findings indicate that macrophage phenotype and function are differentially regulated even at the level of the single receptor, Fms.

Cell Death and Differentiation (2010) 17, 1917-1927; doi:10.1038/cdd.2010.60; published online 21 May 2010

Macrophage colony-stimulating factor (M-CSF, also known as CSF-1) is the primary cytokine for cells of the mononuclear phagocyte lineage such as monocytes, macrophages and osteoclasts, and regulates their development and effector functions. $^{1,2}$ A unique receptor, Fms, the proto-oncogene $c$-fms products and receptor tyrosine kinase, mediates the biological effects of M-CSF. ${ }^{3,4}$ The binding of M-CSF induces the dimerization and activation of the tyrosine kinase activity of Fms. ${ }^{3,4}$ This leads to the autophosphorylation of specific tyrosine residues in the Fms cytoplasmic domain and the subsequent interaction of the phosphorylated tyrosine residues with other signaling proteins, which initiates signaling along specific pathways. ${ }^{3-5}$ The essential role of the M-CSF/ Fms axis in the mononuclear phagocyte lineage has been well established using naturally occurring M-CSF-deficient op/op mice $^{6,7}$ and Fms knockout mice. ${ }^{8}$ Both mice have low body weight, low growth rate and skeletal abnormalities, and are toothless and deficient in most tissue macrophages. ${ }^{6-8}$

Importantly, Lin et al. ${ }^{9}$ recently identified interleukin-34 (IL-34) as the second and functional ligand for Fms. First, they expressed $\sim 3400$ human-secreted proteins, tested their activity in 30 different assays and identified a protein that supported the survival of human peripheral blood monocytes. The protein was a hypothetical protein in the public database (C16orf77) and designated as IL-34. IL-34 mRNA is widely expressed in tissues, including heart, brain, lung, liver, kidney, thymus and spleen. ${ }^{9}$ Next, they screened their library of extracellular domains of transmembrane proteins to block the activity of IL-34 on monocytes and identified Fms as a possible receptor of IL-34. Indeed, the binding of biotinylated IL-34 to human monocytic THP-1 cells was blocked by antiFms antibody or M-CSF, ${ }^{9}$ confirming that IL-34 and M-CSF shared Fms as the receptor. Such alternative ligand has not been identified for Kit and Flt3, the hematopoietic receptor tyrosine kinases that are structurally closely related to Fms. In non-hematopoietic systems, there are several precedents of multiple ligands for a single receptor tyrosine kinase, for example, platelet-derived growth factors and their receptors. ${ }^{10}$ However, in quite contrast to these ligand-receptor systems, M-CSF and IL-34 shared no homology in their amino-acid sequences. ${ }^{9}$ Thus, it is possible to predict that IL-34 and M-CSF are different in their biological activity and signaling, which would provide a clue to understand the physiological significance why two ligands exist for Fms.

IL-34 is shown to support the survival of human peripheral blood monocytes and promote the formation of macrophage colonies in human bone marrow cell cultures. ${ }^{9}$ However, it remains to be analyzed whether the phenotype and function of macrophages differentiated by IL-34 are identical to those by M-CSF. It also remains to be analyzed whether the pattern, kinetics and strength of signal activation by IL-34 are identical to those by M-CSF. Macrophages comprise a heterogeneous

\footnotetext{
${ }^{1}$ Division of Hematopoiesis, Center for AIDS Research, Kumamoto University, Kumamoto, Japan and ${ }^{2}$ Department of Internal Medicine, National Defense Medical College, Saitama, Japan

*Corresponding authors: S Suzu or S Okada, Division of Hematopoiesis, Center for AIDS Research, Kumamoto University, Honjo 2-2-1, Kumamoto 860-0811, Japan. Tel: + 8196373 6522; Fax: + 8196373 6523; E-mail: ssuzu06@kumamoto-u.ac.jp or okadas@kumamoto-u.ac.jp

Keywords: macrophages; M-CSF; IL-34; Fms

Abbreviations: IL-34, interleukin-34; MAb, monoclonal antibody; M-CSF, macrophage colony-stimulating factor; MFI, mean fluorescence intensity; pY, phosphotyrosine

Received 21.10.09; revised 16.4.10; accepted 19.4.10; Edited by H-U Simon; published online 21.5.10
} 
population of cells, and it is thought that their function/ phenotype are regulated by coordinated actions of different classes of cytokines. ${ }^{2,11-14}$ If the macrophages differentiated by IL-34 have some sort of difference from those by M-CSF in their phenotype and signaling, it would mean that the regulation of macrophage phenotype/function is more complicated than thought, even at the single receptor level. Here, we provide the first evidence that these two ligands for Fms, IL-34 and M-CSF, indeed resemble but are not necessarily identical in their biological activity and signal activation.

\section{Results}

Bioactivity of IL-34 is not necessarily identical to that of M-CSF. Recombinant human (rh) IL-34 promoted the survival of human peripheral blood monocytes in a dose-dependent manner, the degree of which was similar to that by rhM-CSF (Figure 1a). IL-34 and M-CSF often induced macrophages with different morphologies (Figure 1b). In donor 1 (upper panels) but not in donor 2 (lower panels), the culture with IL-34 contained less fibroblast-like elongated macrophages (indicated by arrows), which are characteristics of M-CSF-macrophages. ${ }^{11,12}$ The percentage of fibroblast-like elongated macrophages in IL-34-culture was lower than that in M-CSF-culture, in most if not all donors tested (Figure 1b). The level of CD54 (adhesion molecule) was lower, but on the contrary, that of HLA-DR (major histocompatibility complex class II) was higher in IL-34macrophages (Figure 1c). The replication of HIV-1 viruses tended to be higher in IL-34-macrophages (Figure 1d). However, all these differences were quite slight. Moreover, the levels of cell-surface molecules such as CD14, CD16,
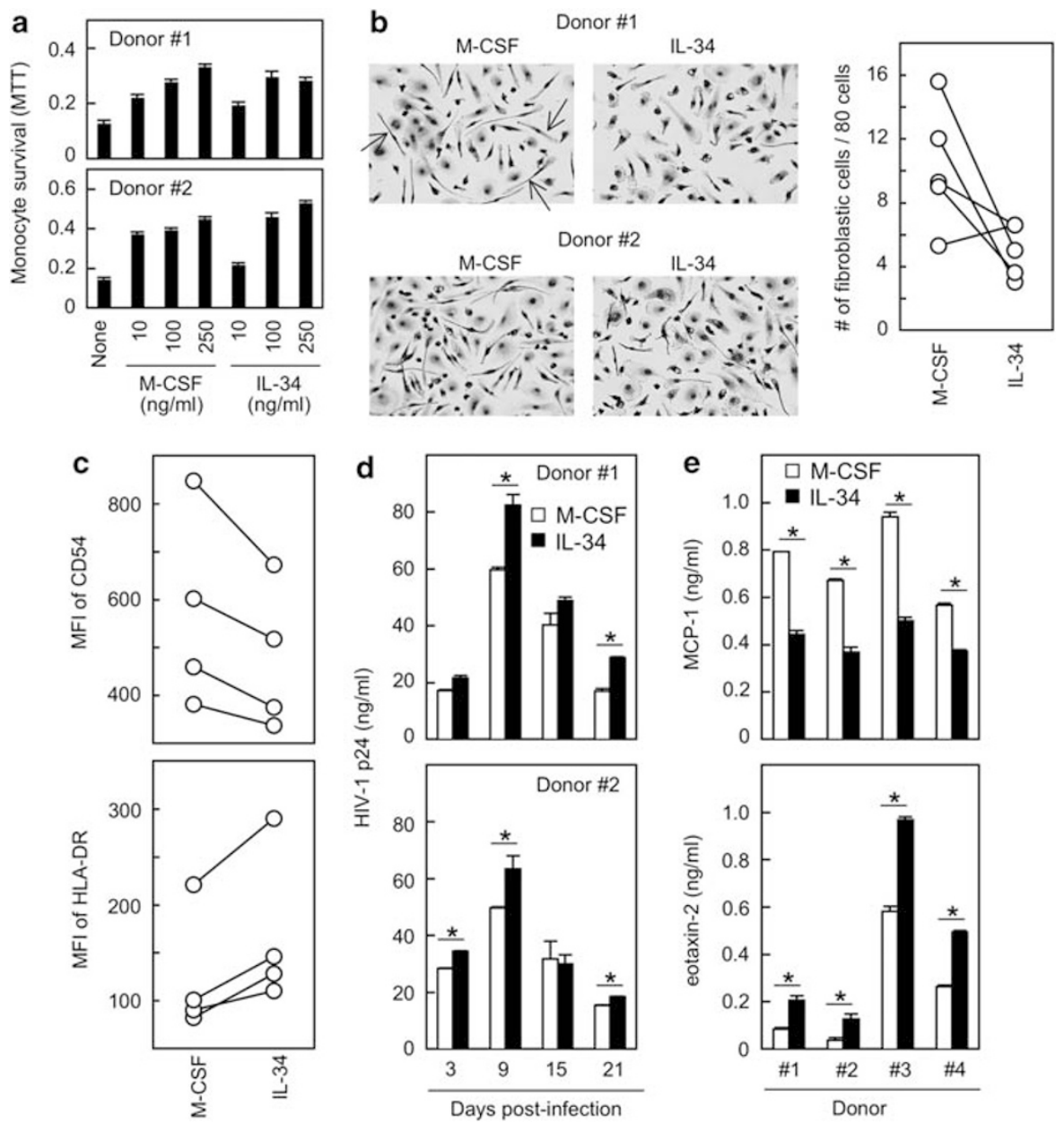

Figure 1 Phenotype and function of IL-34-macrophages. (a and $\mathbf{b}$ ) Peripheral blood monocytes from two different donors were cultured with the indicated concentrations of rhM-CSF or rhlL-34 for 3 days, replaced with the fresh media and cultured for another 3 days. The monocyte survival was determined using the MTT assay and shown as the mean \pm S.D. of triplicate assays. In $\mathbf{b}$, macrophages cultured with $100 \mathrm{ng} / \mathrm{ml} \mathrm{rhM}-\mathrm{CSF}$ or $100 \mathrm{ng} / \mathrm{ml}$ rhlL-34 for 6 days were stained by Wright-Giemsa staining. Fibroblast-like elongated macrophages were counted in three different fields ( 80 cells per field) and the results obtained from five different donors are summarized. (c) Macrophages were prepared as in $\mathbf{b}$ and analyzed for their expression of CD54 and HLA-DR by flow cytometry. The results with macrophages obtained from four different donors were summarized. MFI, mean fluorescence intensity. (d) The day 6-macrophages prepared as in b were infected with HIV-1 viruses (JRFL strain) and the supernatants collected at day 3, 9, 15 or 21 were analyzed for the concentration of HIV-1 p24 Gag proteins by ELISA. Results were shown as the mean \pm S.D. of triplicate assays. (e) The supernatants of macrophages cultured with $100 \mathrm{ng} / \mathrm{ml} \mathrm{rhM-CSF}$ or $100 \mathrm{ng} / \mathrm{ml}$ rhlL-34 for 3 days (from day 3 to 6) were collected and analyzed for the concentration of MCP-1 or eotaxin-2 by ELISA. Data obtained from four different donors were shown. Results were shown as the mean \pm S.D. of triplicate ELISA assays. ${ }^{*} P<0.01$ 
Table 1 Differences and similarities between M-CSF- and IL-34-macrophages

\begin{tabular}{lcc}
\hline Phenotype & $\begin{array}{c}\text { M-CSF- } \\
\text { macrophages }\end{array}$ & $\begin{array}{c}\text { IL-34- } \\
\text { macrophages }\end{array}$ \\
\hline Fibroblast-like macrophages & ++ & + \\
CD54 expression & ++ & + \\
HLA-DR expression & + & ++ \\
CD14 expression & ++ & ++ \\
CD16 expression & ++ & ++ \\
CD11b expression & ++ & ++ \\
CD18 expression & ++ & ++ \\
CD29 expression & ++ & ++ \\
CD49d expression & ++ & ++ \\
CD86 expression & ++ & ++ \\
CD163 expression & ++ & ++ \\
CD204 expression & ++ & ++ \\
Phagocytosis of Escherichia coli & ++ & ++ \\
MCP-1 production & ++ & + \\
Eotaxin-2 production & + & ++
\end{tabular}

$\mathrm{CD} 11 \mathrm{~b}$ (integrin $\alpha \mathrm{M}$ ), CD18 (integrin $\beta 2$ ), CD29 (integrin $\beta 1$ ), CD49d (integrin $\alpha 4$ ), CD163 (scavenger receptor), CD204 (scavenger receptor) or CD86 (costimulatory molecule) were the same between these two macrophages, and their ability of phagocytosis of Escherichia coli was comparable (data not shown). Nevertheless, the ability of these two macrophages to produce chemokines was distinct. The amount of MCP-1 was lower, but on the contrary, the amount of eotaxin-2 was higher in IL-34-macrophages, which was observed in all four donors tested (Figure 1e). The difference and similarity in phenotypes between two macrophages observed in this study are summarized in Table 1.

We next performed assays with a human cell line, TF-1-fms, which was previously established by expressing human Fms into TF-1 cells. ${ }^{15}$ Because TF-1 cells require granulocyte-macrophage (GM)-CSF for their growth but lack the expression of Fms, ${ }^{16}$ neither M-CSF nor IL-34 stimulated the growth of TF-1 cells (data not shown). In contrast, both cytokines stimulated the growth of TF-1-fms cells (Figure 2a), which was abolished by the Fms kinase inhibitor GW2580 ${ }^{17}$ (Figure 2b). Thus, Fms mediated the activity of both cytokines to TF-1-fms cells. Importantly, the morphology of the cells was distinct between the two cultures. rhM-CSF-cultured TF-1-fms cells formed many large aggregates but such large aggregates were few in rhIL-34-cultured cells (Figure 2c, left panels and bar graph). The morphological difference was not due to contaminants in the recombinant proteins, if any, as this was observed even when the supernatants of transfected 293T cells were used as a source of M-CSF or IL-34 (Figure 2c, right panels).

We also performed bioassays with mouse cells. As human IL-34 did not bind mouse Fms unlike human M-CSF (see Figure 8a), we used recombinant mouse (rm) IL-34, and rhMCSF as a reference. The ability of IL-34 to promote the survival of peritoneal macrophages was comparable to that of M-CSF (Figure 3a), and the ability of IL-34 to stimulate the growth of bone marrow progenitor cells (Figure $3 \mathrm{~b}$ ) or M-NFS60 cells (Figure $3 c$ ) was slightly weaker than that of M-CSF. Importantly, in contrast to these results, the difference in their ability to induce cell migration was obvious. As shown (Figure 3d), IL-34 had a markedly weaker ability to induce the migration of J774A. 1 cells. The ability of IL-34 at a higher concentration $(250 \mathrm{ng} / \mathrm{ml})$ was still weaker than that of M-CSF at $100 \mathrm{ng} / \mathrm{ml}$ (Figure 3d). Altogether, our bioassays showed that the biological activity of IL-34 indeed resembled but were not necessarily identical to that of M-CSF. In most assays, IL-34 and M-CSF showed the equivalent ability to support cell growth or survival. However, they were different in the ability to induce the production of chemokines such as MCP-1 and eotaxin-2 in primary macrophages, the morphological change in TF-1-fms cells and the migration of J774A.1 cells.

Signal activation by IL-34 is not necessarily identical to that by M-CSF. To clarify the molecular basis by which IL-34 and M-CSF differently regulate cellular phenotype, we compared the steady-state signal activation status in IL-34-macrophages to that in M-CSF-macrophages. To simultaneously assess the phosphorylation status of various kinases and signaling molecules, we used a dot blot array (Figure 4a). As summarized (Figure 4b), the levels of MAP kinases (MAPK) phosphorylation were slightly higher in IL-34-macrophages (donor 1) or comparable between the two macrophages (donor 2). When analyzed by western blotting, we found no obvious difference in the strength/kinetics of ERK activation between M-CSF- and IL-34-stimulated macrophages during the first $30 \mathrm{~min}$ after stimulation (data not shown). Nevertheless, those of ribosomal S6 kinases and Stat proteins were lower in IL-34-macrophages, in both donors, albeit slightly (Figure 4).

To prove more convincingly that IL-34 and M-CSF elicit different signal activation, we next used human myeloid TF-1-fms cells as a model, because the morphology of the cells cultured with IL-34 was distinct from that with M-CSF (Figure 2c). We found two obvious differences in the overall protein tyrosine phosphorylation between IL-34- and M-CSFstimulated TF-1-fms cells (Figure $5 \mathrm{a}$ ), a strong but transient phosphorylation of several proteins by IL-34 (indicated by asterisks) and a rapid decline of phosphorylation of other several proteins by IL-34 (indicated by arrows). The latter correlated well with a rapid downregulation of Fms in cells treated with IL-34 (Figure 5b). Importantly, the transiently strong but rapid decline of phosphorylation by IL-34 was also observed with Fms itself (Figure 5c). When activated, Fms phosphorylates its own tyrosine residues such as Tyr708, Tyr723 and Tyr809, which triggers the interaction of the activated Fms with downstream signaling molecules. ${ }^{1,3,4}$ As summarized (Figure 5d), IL-34 phosphorylated these and other residues (Tyr546 and Tyr699) more strongly than M-CSF at $1 \mathrm{~min}$ of stimulation (upper panel). The difference in Tyr546 was more obvious than that in other tyrosines. However, these signals by IL-34 declined more rapidly and became weaker than those by M-CSF at $15 \mathrm{~min}$ of stimulation (lower panel). The difference in Tyr546, Tyr699 and Tyr723 was more obvious than that in other tyrosines. The transiently strong but rapid decline of phosphorylation by IL-34 was also observed with focal adhesion kinase (FAK) and an adaptor protein p66Shc (Figure 6), both of which were shown to be phosphorylated by M-CSF. ${ }^{18,19}$ The rapid decline of phosphorylation was also obvious with p52Shc isoform (Figure 6). Collectively, these results indicated that IL-34 temporarily activated Fms and downstream pathways more strongly than 

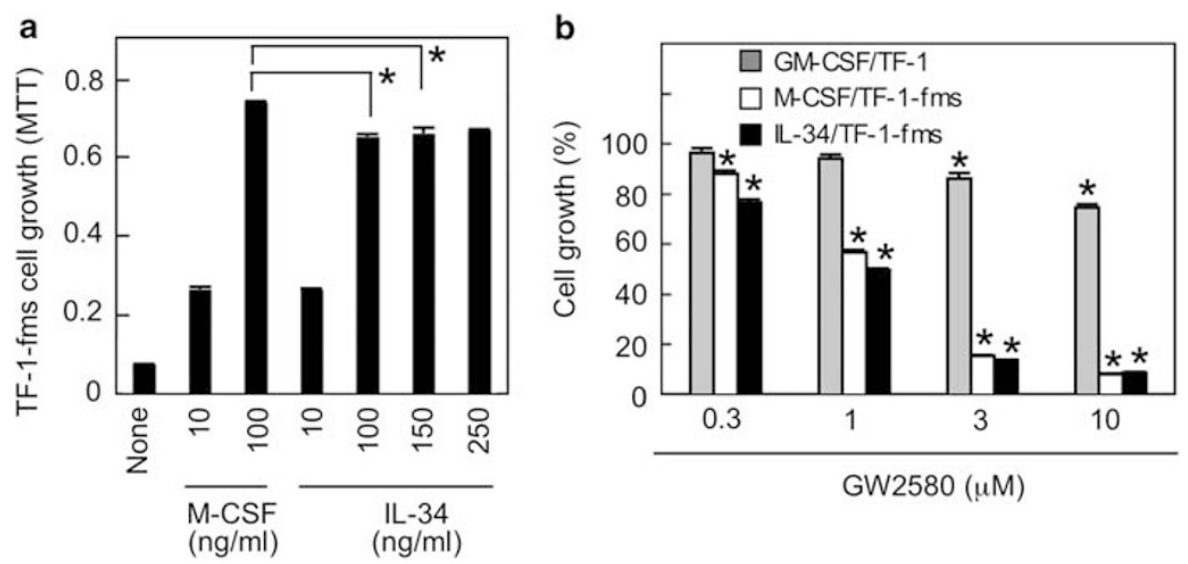

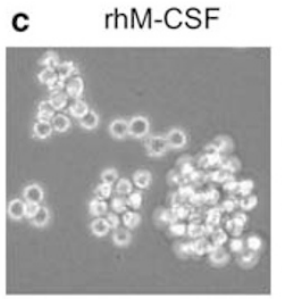

rhIL-34

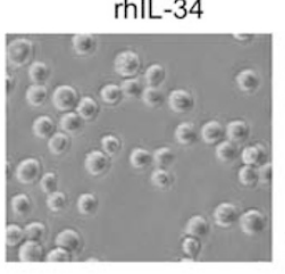

293T-M-CSF

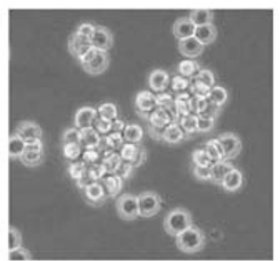

293T-IL-34

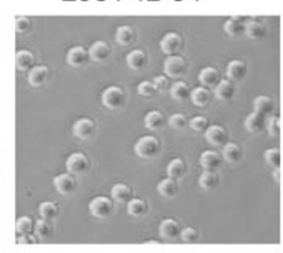

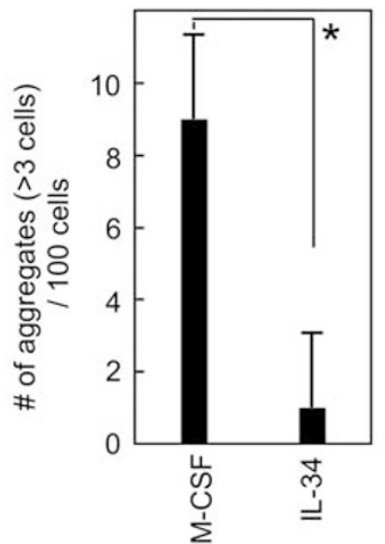

Figure 2 Growth and morphology of TF-1-fms cultured with IL-34. (a) TF-1-fms cells were seeded at $2.5 \times 10^{4}$ cells per ml and cultured with the indicated concentrations of rhM-CSF or rhIL-34 for 3 days. Their growth was assessed using the MTT assay, and shown as the mean \pm S.D. of triplicate assays. (b) TF- 1 cells were seeded at $5 \times 10^{4}$ cells per $\mathrm{ml}$ with $2 \mathrm{ng} / \mathrm{ml} \mathrm{rhGM-CSF}$, and TF-1-fms cells were seeded at $2.5 \times 10^{4}$ cells per ml with $100 \mathrm{ng} / \mathrm{ml} \mathrm{rhM}-\mathrm{CSF}$ or rhlL-34. Cells were then cultured for 3 days in the absence or presence of the indicated concentrations of GW2580, and their growth was determined as in $\mathbf{a}$. The growth inhibition by GW2580 is shown as the mean percent growth relative to control wells (without GW2580) \pm S.D. of triplicate assays. Cells treated with GW2580 at the indicated concentration versus control cells left untreated. (c) In left panels, TF-1-fms cells were cultured with $100 \mathrm{ng} / \mathrm{ml}$ rhM-CSF or $250 \mathrm{ng} / \mathrm{ml}$ rhlL-34 for 3 days. In right panels, TF-1-fms cells were cultured with $20 \% 293 \mathrm{~T}$ cell-conditioned media containing M-CSF-Flag or IL-34-Flag proteins for 3 days. In the bar graph, TF-1-fms cells were cultured with $100 \mathrm{ng} / \mathrm{ml} \mathrm{rhM}-\mathrm{CSF}$ or $250 \mathrm{ng} / \mathrm{ml} \mathrm{rhlL}-34$ for 1 day, and aggregates composed of more than three cells were counted in three different fields ( 100 cells per field). ${ }^{\star} P<0.01$. (a-c) Data shown are representative of three independent experiments with similar results

M-CSF, but those signals were terminated more quickly due to the rapid Fms downregulation.

Possible difference in domains of Fms that IL-34 and M-CSF bind. Mutagenesis studies for M-CSF showed that as few as first 148 amino acids were sufficient for its activity, 7 cysteine residues in the active domains formed three intrachain bonds and one interchain bond, and all these disulfide bonds were essential for its activity. ${ }^{20-22}$ Moreover, despite a lack of appreciable sequence homology, M-CSF, SCF (the ligand for Kit) and Flt3L (the ligand for Flt3) had at least three conserved cysteines in their active domains, which implicated structurally equivalent part of these cytokines in receptor recognition. ${ }^{23}$ Thus, to gain an insight into the difference in the signaling events between IL-34 and M-CSF, we determined the domain of IL-34 required for its activity and compared the number and position of cysteines in the active domains of IL-34 with those of M-CSF. As shown by the $\triangle \mathrm{C} 60$ mutant (Figures $7 \mathrm{a}$ and $\mathrm{b}$ ), the C-terminal 60 amino acids, which contained two cysteines, ${ }^{9}$ were dispensable for IL-34 to stimulate the growth of TF-1-fms cells. The apparent weak activity of $\Delta \mathrm{C} 60$ to stimulate the growth of the cells was due to its low expression (see Figure 7a). Further deletion of $\mathrm{C}$ terminus resulted in abortive expression of mutant IL-34 proteins (data not shown). As shown (Figure 7c), the position of cysteines was less conserved between the active domains of IL-34 and those of M-CSF. Moreover, two out of three cysteines, which were conserved among M-CSF, SCF and Flt3L (indicated by shaded boxes), ${ }^{23}$ were not found in IL-34. These results raised a possibility that IL-34 and M-CSF were different in receptor recognition. To test this possibility, we used the flow cytometry-based ligand binding analysis, ${ }^{24}$ in which target cells were sequentially incubated with Flag-tagged human IL-34 or human M-CSF, biotin-labeled anti-Flag antibody and PE-labeled streptavidin. In this analysis, the fluorescence 

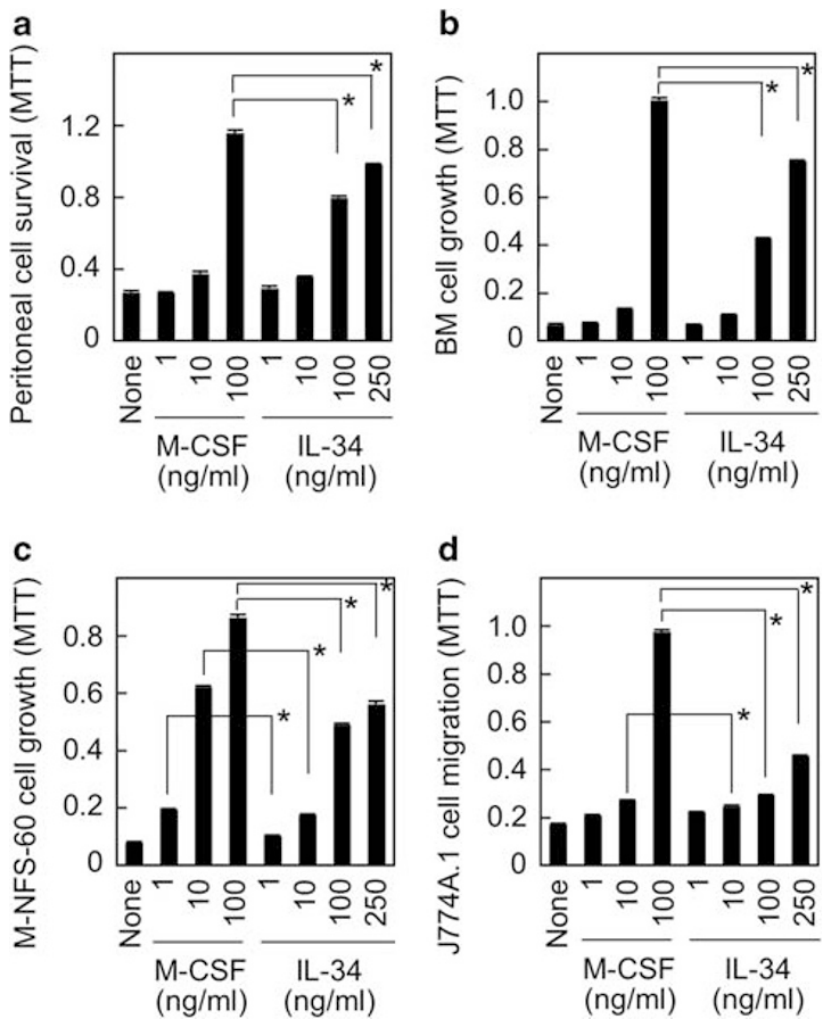

Figure 3 Activity of IL-34 on mouse cells. (a and $\mathbf{b}$ ) Peritoneal cells and femoral bone marrow (BM) cells, both of which were obtained from Balb/C mice, were seeded at $1 \times 10^{5}$ and $1 \times 10^{6}$ cells per ml, respectively, and cultured with indicated concentrations of rhM-CSF or rmIL-34 for 3 days. The cultures were replaced with fresh complete media and incubated for another 3 days. The survival or growth of these cells was monitored using MTT assay. Results were shown as the mean \pm S.D. of triplicate assays. (c) M-NFS-60 cells were seeded at $1 \times 10^{4}$ cells per $\mathrm{ml}$ and cultured with rhM-CSF or rmIL-34 for 3 days. The growth of these cells was monitored using MTT assay. Results were shown as the mean \pm S.D. of triplicate assays. (d) The migration of J774A.1 cells was measured using a transmigration chamber assay with $8 \mu \mathrm{m}$ pore size inserts. rhM-CSF or rmlL-34 was added to wells at the indicated concentrations. The number of J774A.1 cells migrated through the inserts was monitored using MTT assay. Results were shown as the mean \pm S.D. of triplicate assays. (a-d) Data shown are representative of two independent experiments with similar results. ${ }^{*} P<0.01$

signal was observed with Fms-positive TF-1-fms cells but not with Fms-negative TF-1 cells (Figure 8a). Moreover, in agreement with the finding that human M-CSF, but not human IL-34, stimulated the growth of mouse Fms-positive M-NFS-60 cells (data not shown), the fluorescence signal was observed only when the cells were incubated with M-CSF-Flag (Figure 8a). Thus, the observed signal indeed reflected the specific binding of these Flag-tagged ligands. Using this system, we first confirmed that purified rhIL-34 inhibited the binding of M-CSF-Flag to TF-1-fms cells and vice versa (Figure $8 \mathrm{~b}$ ). We also confirmed that an anti-Fms monoclonal antibody (MAb) clone $12-2 D 6^{25}$ inhibited both the binding of M-CSF-Flag to TF-1-fms cells and the binding of IL-34-Flag to the cells (Figure 8c, upper panels). Another anti-Fms MAb clone 2-4A5 ${ }^{25}$ inhibited the M-CSF-Flag binding more efficiently than the MAb clone 12-2D6 (lower left panel). However and of importance, the 2-4A5 clone did not inhibit the IL-34-Flag binding to TF-1-fms cells at all (lower right panel). Consistent with the result, the clone 2-4A5 completely inhibited the growth of TF-1-fms cells by M-CSF but not by IL-34 (data not shown). These results suggested that IL-34 and M-CSF bound overlapping but different domains of Fms. Taken all together, our present study showed that IL-34 and M-CSF indeed resembled but were not necessarily identical in their biological activity and signal activation kinetics/strength, which might be caused by the difference in their structure, Fms domains that they bound and the rate of Fms downregulation.

\section{Discussion}

Macrophages comprise a heterogeneous population of cells with various phenotypes and functions, which are distinctly regulated by cytokines such as M-CSF and GM-CSF. Indeed, macrophages derived from these cytokines showed marked differences in the morphology, the ability to support HIV-1 replication and the production of cytokine or chemokine..$^{2,11-14}$ These differences are basically due to the difference in the structure of their receptors. ${ }^{2}$ In this study, we showed that macrophage phenotype and function were differently regulated even at the level of the single receptor Fms, by using IL-34 and M-CSF.

We showed that IL-34-macrophages and M-CSF-macrophages were not necessarily identical in their phenotype or function. The replication of HIV-1 tended to be higher in IL-34-macrophages (Figure 1d), which was consistent with the finding that the levels of MAPK phosphorylation were slightly higher in IL-34-macrophages or comparable between two macrophages (Figure 4), as the activation of MAPK pathway was required for HIV-1 replication. ${ }^{26}$ The notable difference was the production of chemokines. IL-34-macrophages produced lesser MCP-1 but more eotaxin-2 than M-CSF-macrophages (Figure 1e). The lesser MCP-1 production might be due to the lower phosphorylation of Stat family proteins in IL-34-macrophages (Figure 4b), as the activation of Stat was required for the expression of MCP-1. ${ }^{27,28}$ Given that chemokines have a crucial role in immune and inflammatory reactions ${ }^{29}$ and thus their expression should be tightly regulated, ${ }^{30}$ our result implies that IL-34 and M-CSF are differently involved in those reactions. Using cultured cell lines, we further showed that IL-34 and M-CSF differently regulated cellular phenotypes. The most notable differences were the migration of J774A.1 cells (Figure $3 \mathrm{~d}$ ) and the morphology of TF-1-fms cells (Figure $2 \mathrm{c}$ ), which was likely to be due to a differential regulation of the reorganization of actin cytoskeleton or the expression of adhesion molecules. These results may also support the idea that these cytokines are differently involved in immune and inflammatory reactions, as the recruitment of macrophages at specific sites is important in achieving a localized and efficient reaction.

It is well known that the rate of downregulation of receptor tyrosine kinases, which associates with their endocytosis, ${ }^{31}$ regulates the signal kinetics or strength. For instance, macrophages obtained from mice lacking $\mathrm{Cbl}$, a ubiquitin ligase that targets Fms to the endocytic machinery, ${ }^{32,33}$ exhibited a delayed downregulation of Fms, a prolonged tyrosine phosphorylation of Fms and downstream molecules, and an enhanced growth response to M-CSF. ${ }^{34-36}$ In this 

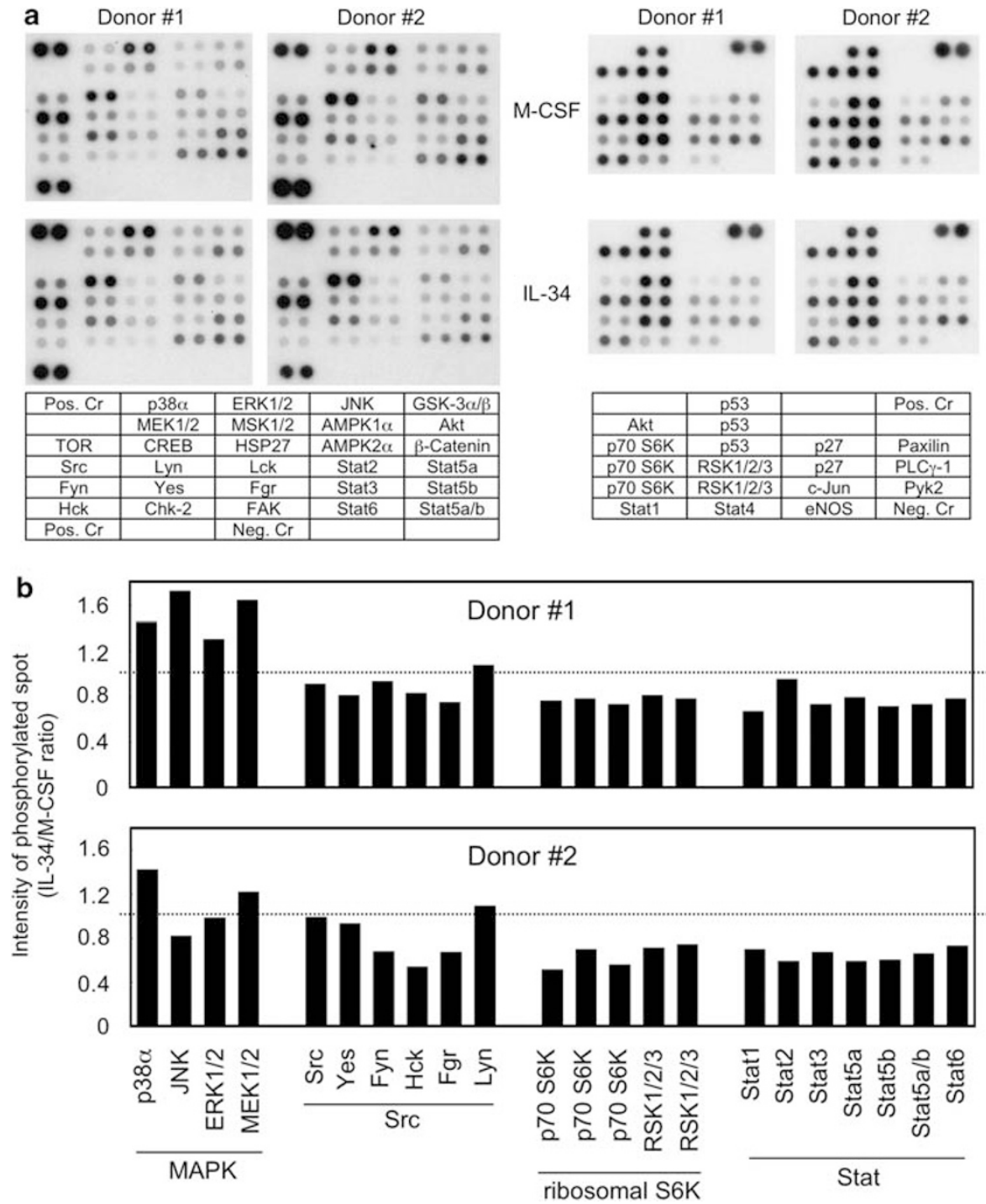

Figure 4 Phosphorylation levels of signal molecules in IL-34-macrophages. (a and $\mathbf{b}$ ) The day 6-macrophages, which were prepared by culturing monocytes from two different donors with $100 \mathrm{ng} / \mathrm{ml} \mathrm{rhM}-\mathrm{CSF}$ or $100 \mathrm{ng} / \mathrm{ml}$ rhlL-34, were analyzed for the phosphorylation levels of various kinases and signal molecules using the human phosphokinase array. Pos. Cr, positive control; Neg. Cr, negative control. Data shown in $\mathbf{b}$ were the scanned images of films exposed to the arrays for 1 min and results from selected targets. The average signal of the pair of duplicate spots was determined for selected molecules, and results were shown in $\mathbf{b}$ as the relative change between M-CSF-macrophages and IL-34-macrophages. As for p70 ribosomal S6 kinases (S6K) and RSK1/2/3, results with different capture antibodies were shown. (See http://www.rndsystems.com/ for details about antibodies used for the array)

study, we showed that IL-34 temporarily activated Fms and downstream pathways more strongly than M-CSF (Figures 5a, c and 6), but those signals were terminated more quickly due to the rapid Fms downregulation (Figure 5b). Thus, it is reasonable to conclude that this difference in the earliest signaling events leads to the observed cellular phenotypic differences. The rapid termination of signal might explain why the steady-state signal activation status was generally low in IL-34-macrophages (Figure 4). Among the autophosphorylation sites of Fms, Tyr546 was the most typical site showing the strong but transient phosphorylation upon IL-34-stimulation (Figures $5 c$ and d). However, signaling molecules that interact with this site have not been identified yet. ${ }^{1,4,37}$ The identification of such molecules will facilitate the understanding of signaling cascades unique to IL-34.
Using Biacore analysis, Lin et al. ${ }^{9}$ previously showed that M-CSF and IL-34 bound the extracellular domain of Fms with a $K_{\mathrm{d}}$ of $34 \mathrm{pM}$ and about $1 \mathrm{pM}$, respectively, which appeared to explain our finding that the inhibition of M-CSFFms binding by IL-34 was more effective than the inhibition of IL-34-Fms binding by M-CSF (Figure 8b). Our results also suggested the difference in the disulfide bond formation between IL-34 and M-CSF (Figure 7c) and Fms domains that they recognized (Figure $8 \mathrm{c}$ ). Thus, it was highly likely that IL-34 and M-CSF bound overlapping but different domains of Fms with different affinities, and thereby elicited the different Fms activation kinetics and strength. This idea should be further confirmed by determining the crystal structure of the complex between IL-34 and Fms, as done with M-CSF-Fms complex. ${ }^{38}$ 


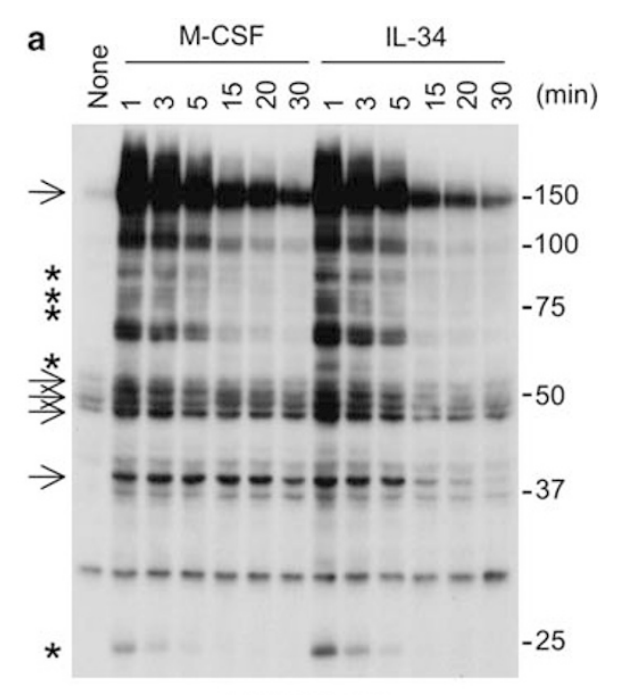

Blot: anti-pY

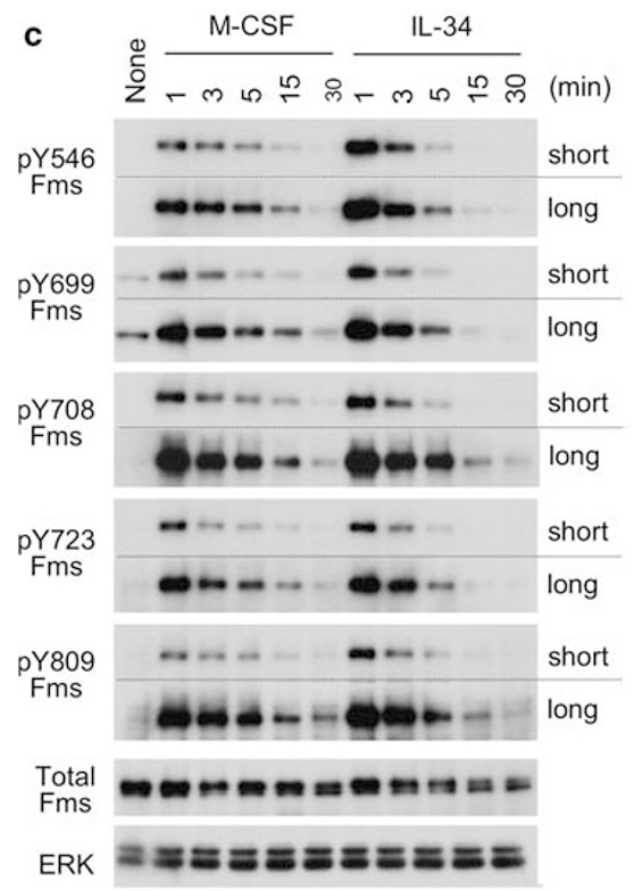

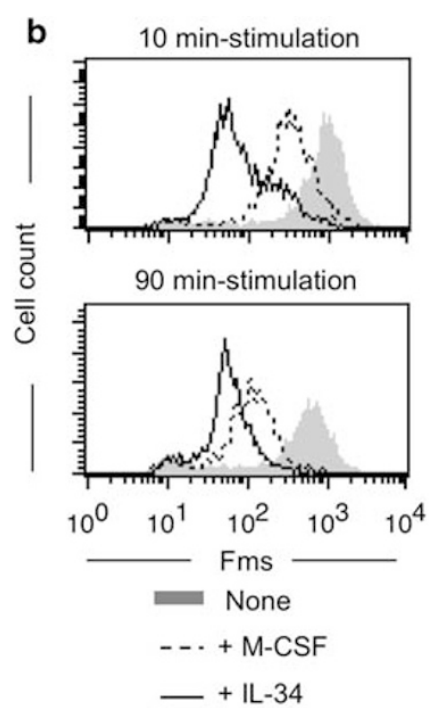

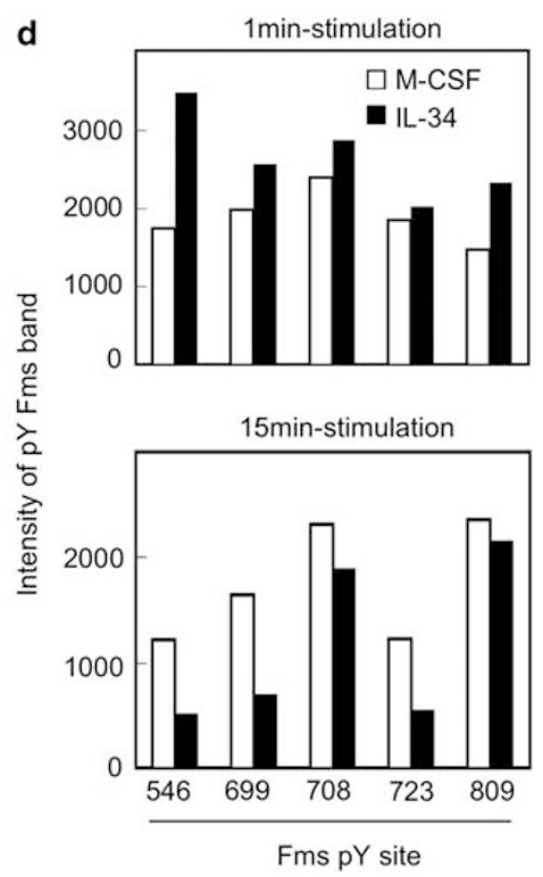

Figure 5 Tyrosine phosphorylation and Fms downregulation by IL-34. (a) TF-1-fms cells were M-CSF-depleted for $14 \mathrm{~h}$ and then stimulated with $100 \mathrm{ng} / \mathrm{ml} \mathrm{rhM}-\mathrm{CSF}$ or $100 \mathrm{ng} / \mathrm{ml} \mathrm{rhlL}-34$ for the indicated periods at $37^{\circ} \mathrm{C}$. The total cell lysates were analyzed for tyrosine-phosphorylated proteins by western blotting. See text for details of the arrows and asterisks. (b) TF-1-fms cells were M-CSF-depleted for $6 \mathrm{~h}$, left untreated (none) or treated with $100 \mathrm{ng} / \mathrm{ml} \mathrm{rhM-CSF}$ or $100 \mathrm{ng} / \mathrm{ml}$ rhlL- 34 for 10 or $90 \mathrm{~min}$ at $37^{\circ} \mathrm{C}$, and then analyzed for the cell-surface expression of Fms by flow cytometry with PE-labeled anti-Fms antibody (clone 3-4A4). (c) TF-1-fms cells were M-CSF-depleted for 14 $\mathrm{h}$ and then stimulated with $100 \mathrm{ng} / \mathrm{ml} \mathrm{rhM}-\mathrm{CSF}$ or $100 \mathrm{ng} / \mathrm{ml} \mathrm{rhlL}-34$ for the indicated periods at $37^{\circ} \mathrm{C}$. The total cell lysates were subjected to western blotting. Antibodies used were as follows: anti-phosphorylated Fms (Tyr546, Tyr699, Tyr708, Tyr723 and Tyr809), anti-Fms (total) and anti-ERK. The film was exposed to the blot for 10 s (short exposure) or $1 \mathrm{~min}$ (long exposure). The ERK blot is a loading control. (d) The profiles, which were created by quantifying the band pixel densities on $\mathbf{c}$, were shown. The upper ( 1 min stimulation with either M-CSF or IL-34) and lower panel (15 min stimulation) was obtained by using the short-exposure and the long-exposure film, respectively. (a-d) Data shown are representative of two independent experiments with similar results

rmIL-34 showed the marked weak activity in the migration of J774A. 1 cells (Figure $3 d$ ). The weak in vitro activity of mouse IL-34 was apparently consistent with the finding that overall phenotypes of M-CSF-deficient op/op mice and Fms knockout mice were quite similar, although the osteopetrosis in femurs and the depletion of macrophages in kidney were slightly severe in Fms knockout mice. ${ }^{8}$ However, the activity of human
IL-34 was not always weaker than that of M-CSF, as shown in this study. Thus, in vivo role of IL-34 may be different between mice and humans.

In summary, we showed that two ligands for Fms, IL-34 and M-CSF, indeed resembled but were not necessarily identical in their biological activity and signal activation. In other words, we showed that macrophage phenotype and function were 

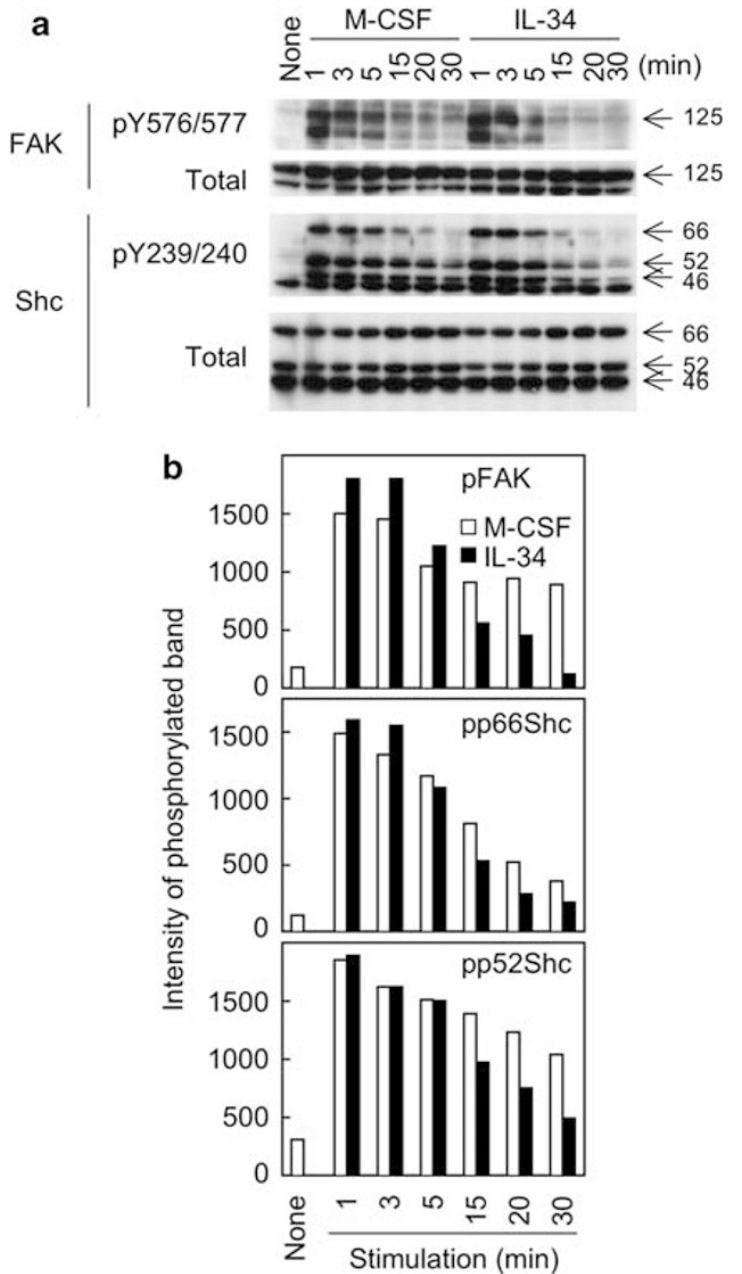

Figure 6 Tyrosine phosphorylation of downstream molecules. (a) TF-1-fms cells were M-CSF-depleted for $14 \mathrm{~h}$ and then stimulated with $100 \mathrm{ng} / \mathrm{ml}$ rhM-CSF or $100 \mathrm{ng} / \mathrm{ml} \mathrm{rhlL}-34$ for the indicated periods at $37^{\circ} \mathrm{C}$. The total cell lysates were subjected to western blotting. Antibodies used were as follows: anti-phosphorylated FAK (Tyr576/577), anti-FAK (total), anti-phosphorylated Shc (Tyr239/240) and anti-Shc (total). (b) The profiles, which were created by quantifying the band pixel densities on a, were shown. (a and $\mathbf{b}$ ) Data shown are representative of three independent experiments with similar results

differentially regulated even at the level of the single receptor Fms. Moreover, our study provided a new example showing that cellular response to cytokines was tightly regulated by the rate of receptor downregulation and the kinetics/strength of receptor activation. However, it is still unclear why these functionally different ligands exist for Fms. For the reason mentioned above, it may be difficult to apply results obtained from studies with mice, for example IL-34 knockout mice, to gain insights into the role of IL-34 in humans. Thus, it is important to analyze the steady-state in vivo level of IL-34 proteins and its alteration in various human disorders. More functional assays as well as comprehensive transcriptional profiling analyses ${ }^{11,39}$ are also needed to fully understand the phenotype, function and signaling of IL-34-macrophages.

\section{Materials and Methods}

Recombinant proteins. rhlL-34 and rmlL-34 with a molecular mass of approximately $70 \mathrm{kDa}$ were purchased from R\&D Systems (Minneapolis, MN, USA). a
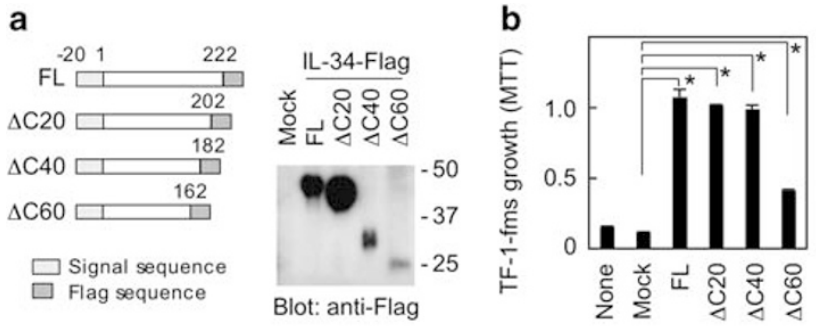

C

$$
\begin{array}{cc}
\text { M-CSF EEVSEYCSHMIG----SGHLQSLQRLIDSQMETSCRITFEFVQEQLKDPVGYKKAFL } 55 \\
\text { IL-34 }
\end{array}
$$

Figure 7 Active domains of IL-34 and their amino-acid sequences. (a and $\mathbf{b}$ ) The full-length (FL) IL-34-Flag and its mutants used ( $\Delta$ C20-Flag, $\Delta$ C40-Flag and $\Delta$ C60-Flag) were schematically shown. The empty plasmid (Mock) or plasmids encoding these IL-34 proteins were transfected into 293T cells, and the supernatants were analyzed for the amount of those proteins with anti-Flag antibody. In $\mathbf{b}$, the supernatants were subjected to the biological assay with TF-1fms cells. The cells were seeded at $2.5 \times 10^{4}$ cells per ml and cultured with $20 \%$ 293T cell-conditioned media for 3 days. Their growth was assessed using the MTT assay, and shown as the mean \pm S.D. of triplicate assays. Data shown are representative of two independent experiments with similar results. (c) The aminoacid sequences of the active domain of M-CSF ${ }^{19,20}$ and those of IL-34- $\Delta$ C60 were compared. All cysteine residues were boxed. The shaded boxes indicated the cysteines conserved among M-CSF, SCF and Flt3L ${ }^{21}$. ${ }^{*} P<0.01$

Purified rhM-CSF with a molecular mass of approximately $85 \mathrm{kDa}^{15}$ was a gift from Morinaga Milk Industry (Kanagawa, Japan). The purity and endotoxin level of these preparations were $>95 \%$ as determined by SDS-PAGE and $<1.0 \mathrm{EU}$ (endotoxin unit) per $1 \mu \mathrm{g}$ as determined by the LAL method, respectively.

Preparation of primary macrophages. Heparinized venous blood was collected from healthy donors, after informed consent was obtained in accordance with the Declaration of Helsinki Principles. The approval for this study was obtained from the Kumamoto University Medical Ethical Committee. Mononuclear cells obtained using LSM reagent (MP Biomedicals, Solon, OH, USA) were suspended into RPMI 1640 medium- $1 \%$ FCS at $1 \times 10^{6}$ cells per ml and seeded into multiwell plates. Monocytes were enriched by adherence to plates for $1 \mathrm{~h}$ at $37^{\circ} \mathrm{C}$, and nonadherent cells were removed by extensive washing with PBS. Then, the adherent monocytes were differentiated into macrophages by culturing with RPMI 1640-10\% FCS containing either rhlL-34 or rhM-CSF. After 3 days, the cultures were replaced with fresh complete media and incubated for another 3 days. The purity of the day 6-macrophages prepared by this method was routinely more than $95 \%$ when assessed by the expression of CD14, as reported previously. ${ }^{16}$ The number of macrophages was monitored using MTT reagent (Sigma, St Louis, MO, USA). In brief, MTT was added to each well at a final concentration of $0.5 \mathrm{mg} / \mathrm{ml}$, and $0.01 \mathrm{~N}$ $\mathrm{HCl}$-isopropanol was added after the incubation for $4 \mathrm{~h}$ at $37^{\circ} \mathrm{C}$. The absorbance of wells was measured at $595 \mathrm{~nm}$ using a Multiskan microplate reader (Thermo Electron, Vantaa, Finland). Macrophages were also stained with Wright-Giemsa.

Expression of cell-surface molecules on macrophages. The expression of surface molecules on macrophages was determined by flow cytometry on a FACSCalibur using CellQuest software (Becton Dickinson, Mountain View, CA, USA). The day 6-macrophages were detached from wells using enzymefree Cell Dissociation Buffer (Gibco, Grand Island, NY, USA) and immediately subjected to flow cytometric analysis. Labeled antibodies used were PE-labeled anti-CD54 (Pharmingen, San Jose, CA, USA) and FITC-labeled anti-HLA-DR (Caltag, Burlingame, CA, USA). 
a

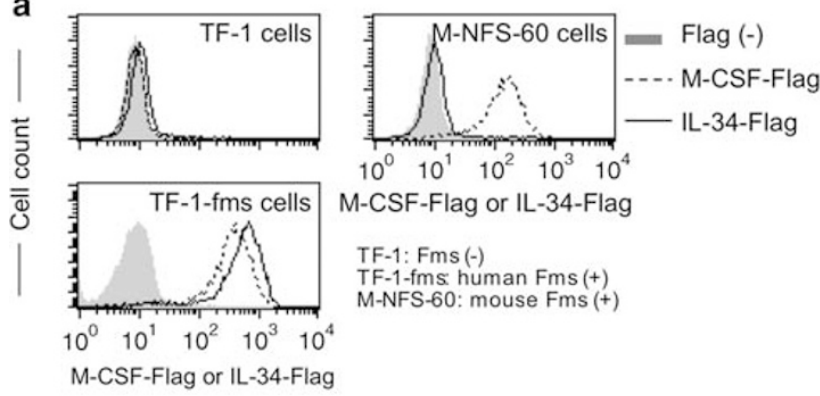

b
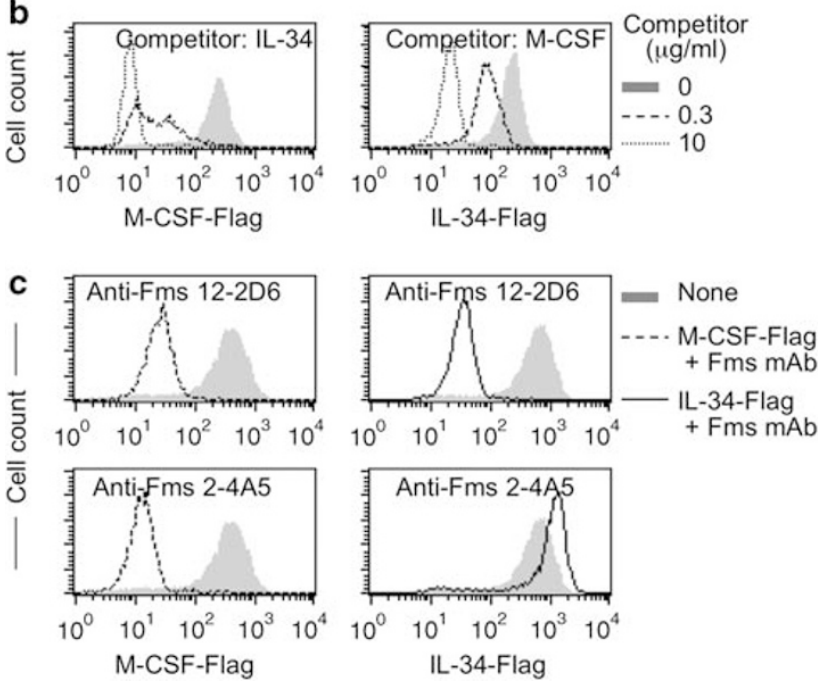

Figure 8 Flow cytometry-based IL-34 binding and competition analyses. (a) Before the analyses, TF-1 (Fms-negative), TF-1-fms (human Fms-positive) and M-NFS-60 cells (mouse Fms-positive) were growth factor-depleted for $6 \mathrm{~h}$. These cells were first incubated with the diluted supernatants of 293T cells transfected with empty plasmid (Flag (-)), M-CSF-Flag plasmid or IL-34-Flag plasmid. Then, these cells were stained sequentially with biotin-labeled anti-Flag antibody and PE-labeled streptavidin. The binding of Flag-tagged proteins to these cells was detected by flow cytometry. (b and c) TF-1-fms cells were M-CSF-depleted for $6 \mathrm{~h}$ and then incubated with the diluted supernatants of $293 \mathrm{~T}$ cells transfected with M-CSF-Flag plasmid, or IL-34-Flag plasmid, in the presence of competitors. In $\mathbf{b}$ (the cross competition), rhlL-34 or rhM-CSF was added to the incubation mixtures at a final concentration of 0.3 or $10 \mu \mathrm{g} / \mathrm{ml}$. In c (the antibody competition), anti-Fms rat $\operatorname{lgG}$ (clone $12-2 \mathrm{D} 6$ or 2-4A5) was added to the incubation mixtures at a final concentration of $100 \mu \mathrm{g} / \mathrm{ml}$. The binding of Flag-tagged proteins to the cells was detected by flow cytometry. (a-c) The staining and washing steps were carried out on ice. Data shown are representative of three independent experiments with similar results

HIV-1 replication in macrophages. The JRFL strain of HIV-1 was prepared by transfecting the infectious proviral plasmid ${ }^{40}$ into $293 \mathrm{~T}$ cells. The transfection was performed using Lipofectamine 2000 (Invitrogen, Carlsbad, CA, USA) as described previously. ${ }^{22}$ Then, macrophages cultured with either rhIL-34 or rhM-CSF for 6 days were incubated with $250 \mu$ of the 293T cell supernatants containing JRFL HIV-1 viruses (50 ng p24 Gag proteins per $\mathrm{ml}$ ) for $2 \mathrm{~h}$ at $37^{\circ} \mathrm{C}$. The cells were washed twice with PBS to remove unbound viruses and cultured with RPMI $1640-10 \%$ FCS containing either rhlL-34 or rhM-CSF. One-half of the culture media was replaced with the complete media every 3 days. The culture supernatants were analyzed for the concentration of p24 Gag proteins by ELISA (ZeptoMetrix, Buffalo, NY, USA) to monitor viral replication.

Chemokine production by macrophages. The supernatants of macrophages cultured with rhlL-34 or rhM-CSF for 3 days (from day 3 to 6 ) were collected and analyzed for the concentration of MCP-1 or eotaxin-2 by ELISA (R\&D Systems).

Phosphorylation level of signaling molecules in macrophages. The level of phosphorylation of 46 signaling molecules was analyzed using a human phosphokinase array (R\&D Systems) according to the manufacturer's instructions. Briefly, the extracts of macrophages cultured for 6 days with rhlL-34 or rhM-CSF were added to the dot blot array $(100 \mu \mathrm{g}$ total protein per membrane), onto which the capture antibodies had been spotted. After the incubation with the secondary antibody mixtures, the signal was detected using the ECL Plus Western Blotting System (GE Healthcare, Buckinghamshire, UK). The intensity of spots on scanned film images was quantified using Quantity One software (Bio-Rad, Tokyo, Japan)

Bioassays with mouse cells. Peritoneal cells and femoral bone marrow cells, both of which were obtained from Balb/C mice, were suspended in RPMI $1640-10 \%$ FCS at $1 \times 10^{5}$ and $1 \times 10^{6}$ cells per ml, respectively, and cultured with rmlL-34 or rhM-CSF for 3 days. The cultures were replaced with fresh complete media and incubated for another 3 days. All experiments were performed according to the guidelines of the Institutional Animal Committee of Kumamoto University. Mouse myeloid M-NFS-60 cells (purchased from the ATCC, Manassas, VA, USA), which express mouse Fms, ${ }^{41}$ were maintained with RPMI $1640-10 \%$ FCS-100 ng/ $\mathrm{ml}$ rhM-CSF. The cells were suspended at $1 \times 10^{4}$ cells per $\mathrm{ml}$ and cultured with rmlL-34 or rhM-CSF for 3 days. The survival or growth of these cells was monitored using MTT assay as described above. The cell migration was measured using a transmigration chamber assay with $8 \mu \mathrm{m}$ pore size inserts (Corning, Corning, NY, USA). Briefly, the inserts were placed into 24-well plates containing RPMI 1640$10 \%$ FCS in the absence or presence of rmIL-34 or rhM-CSF. Mouse J774A.1 cells $\left(2.5 \times 10^{5}\right.$ cells per $100 \mu$ l RPMl $1640-10 \%$ FCS $)$ were then added onto the inserts and incubated at $37^{\circ} \mathrm{C}$ for $12 \mathrm{~h}$. The number of cells migrated through the inserts was monitored using MTT assay.

Culture of human hematopoietic cell lines. Human myeloid leukemia TF-1 cells ${ }^{15,42}$ were maintained with RPMl 1640-10\% FCS-2 ng/ml rhGM-CSF (Peprotech). TF-1-fms cells obtained by introducing human c-fms plasmid into the parental TF-1 cells ${ }^{15}$ were routinely maintained with RPMI $1640-10 \%$ FCS-100 ng/ml rhM-CSF-200 $\mu \mathrm{g} / \mathrm{ml}$ G418 (Calbiochem, Darmstadt, Germany). The growth of these cells was monitored using MTT assay as described above. In a selected experiment, an Fms kinase inhibitor GW2580 ${ }^{17}$ (purchased from Calbiochem) was used.

Western blotting. Western blotting with TF-1-fms cells was performed essentially as described previously. ${ }^{5,22,42}$ Briefly, the cells maintained with rhMCSF were M-CSF-depleted for $14 \mathrm{~h}$ in RPMI 1640-10\% FCS and then stimulated with rhIL-34 or rhM-CSF for the indicated periods at $37^{\circ} \mathrm{C}$. Then, $1 \times 10^{6}$ cells were lysed with $100 \mu$ l Nonidet P-40 buffer (1\% Nonidet P-40, $50 \mathrm{mM}$ Tris and $150 \mathrm{mM}$ $\mathrm{NaCl}$ ) containing protease inhibitors ( $1 \mathrm{mM}$ EDTA, $1 \mathrm{mM}$ PMSF, $1 \mu \mathrm{g} / \mathrm{ml}$ aprotinin, $1 \mu \mathrm{g} / \mathrm{ml}$ leupeptin and $1 \mu \mathrm{g} / \mathrm{ml}$ pepstatin) and phosphatase inhibitors ( $1 \mathrm{mM} \mathrm{Na}_{3} \mathrm{VO}_{4}$ and $1 \mathrm{mM} \mathrm{NaF}$ ). Total cell lysates were then subjected to western blotting. Antibodies used were as follows: anti-phosphotyrosine (pY99; Santa Cruz Biotechnology, Santa Cruz, CA, USA), anti-phospho-specific Fms (Tyr546, Tyr699, Tyr708, Tyr723 and Tyr809; all from Cell Signaling, Danvers, MA, USA), anti-Fms (H-300; Santa Cruz Biotechnology), anti-ERK (K-23; Santa Cruz Biotechnology), anti-phospho-specific FAK (Tyr576/577; Cell Signaling), anti-FAK (Cell Signaling), anti-phospho-Shc (Tyr239/240; Cell Signaling) and anti-Shc (Upstate, Lake Placid, NY, USA). Detection was performed with HRP-labeled secondary antibodies (GE Healthcare) and the ECL Plus Western Blotting System. The intensity of bands on scanned film images was quantified using Quantity One software.

Fms downregulation. The downregulation of the cell-surface Fms upon IL-34 or M-CSF binding was determined by flow cytometry on a FACSCalibur. TF-1-fms cells maintained with rhM-CSF were M-CSF-depleted for $6 \mathrm{~h}$, and then left untreated or treated with $100 \mathrm{ng} / \mathrm{ml}$ rhlL-34 or $100 \mathrm{ng} / \mathrm{ml} \mathrm{rhM}-\mathrm{CSF}$ for 10 or $90 \mathrm{~min}$ at $37^{\circ} \mathrm{C}$. The ice-cold PBS was added to the cell suspensions and the cells were analyzed for the expression of Fms using PE-labeled anti-Fms (clone 3-4A4 ${ }^{25}$; Santa Cruz Biotechnology). The staining and washing steps were carried out on ice. We selected the clone 3-4A4 for Fms staining, as the clone inhibited neither IL-34-Fms nor M-CSF-Fms binding (Chihara T and Suzu S, unpublished results). 
Preparation of Flag-tagged IL-34 and M-CSF. In this study, we prepared human IL-34 proteins with Flag tag sequence (DYKDDDDK) at its $C$ terminus (IL-34-Flag) for the ligand binding analysis (see below). Human M-CSF-Flag was prepared as described previously. ${ }^{24}$ Using the full-length IL-34 cDNA obtained by PCR as a template, we prepared IL-34-Flag CDNA also by PCR. To determine the active domain of IL-34, we further prepared Flag-tagged mutant IL-34 CDNAs that lacked C-terminal 20, 40 and 60 amino acids ( $\Delta \mathrm{C} 20, \Delta \mathrm{C} 40$ and $\triangle \mathrm{C60}$; see Figure 7a). The PCR primers used were as follows:

$5^{\prime}$-GGGGACGAGGAACACCACCAT-3' (the common upstream primer), 5'-ATCCGCAGTCACCATCCAGGG-3' (for the full-length IL-34), 5'-TTCATTTATC ATCATCATCTTTATAATCGGGCAAGAGGCC-3' (for the full-length IL-34-Flag), 5'-CCTATTTATCGTCGTCATCTTTGTAGTCCGTGGAGTGAGG-3' (for the IL-34$\triangle$ C20-Flag), $\quad 5^{\prime}$-CCTACTTGTCGTCGTCGTCCTTATAATCATACTGCAATGA-3' (for the IL-34- $\triangle$ C40-Flag) and $5^{\prime}$-CTCATTTATCATCATCATCTTTATAATCGCTTT GTTTACA-3' (for the IL-34- $\Delta$ C60-Flag).

The PCR products were cloned into pCR2.1 vector (Invitrogen) and the nucleotide sequences were verified using a BigDye Terminator v3.1 Cycle Sequencing Kit (Applied Biosystems, Foster City, CA, USA) and ABI PRISM 3100 Genetic Analyzer (Applied Biosystems). The insert cDNAs were subcloned into pcDNA3.1 expression vector (Invitrogen), and the expression plasmids were transfected into 293T cells using Lipofectamine 2000 as described previously. ${ }^{16,24}$ The supernatants collected after 2 days were analyzed for the expression of Flagtagged proteins by western blotting with anti-Flag antibody (clone M2; Sigma) and the activity to stimulate the growth of TF-1-fms cells, or subjected to the ligand binding analysis. The sequence alignment was performed using the ClustalW algorithm. ${ }^{43}$

Ligand binding and competition analyses. The binding of IL-34-Flag or M-CSF-Flag proteins to hematopoietic cell lines was assessed by the flow cytometry-based analysis. ${ }^{24}$ Before assay, the supernatants of transfected $293 \mathrm{~T}$ cells were analyzed for the amount of IL-34-Flag or M-CSF-Flag proteins by western blotting with anti-Flag M2 antibody, and appropriately diluted with DMEM medium$10 \%$ FCS. TF- 1 cells maintained with rhGM-CSF, and TF- 1 -fms and M-NFS- 60 cells maintained with rhM-CSF were factor-depleted in RPMI 1640-10\% FCS for $6 \mathrm{~h}$ at $37^{\circ} \mathrm{C}$. The factor-depleted cells were first incubated with the diluted $293 \mathrm{~T}$ cell supernatants on ice for $20 \mathrm{~min}$. After washing twice with chilled PBS-1\% BSA, the cells were then incubated with biotin-labeled anti-Flag M2 antibody $(10 \mu \mathrm{g} / \mathrm{ml}$ in PBS- $1 \% \mathrm{BSA}$ ) for $20 \mathrm{~min}$ on ice. After washing as above, the cells were finally incubated with PE-labeled streptavidin ( $5 \mu \mathrm{g} / \mathrm{ml}$; Pharmingen) for $20 \mathrm{~min}$ on ice, and analyzed on a FACSCalibur. In the competition analysis, the M-CSF-depleted TF-1-fms cells were incubated with the diluted 293T cell supernatants in the presence of rhlL-34, rhM-CSF or anti-Fms antibody. Rat monoclonal anti-Fms antibodies ${ }^{25}$ used were the clone 12-2D6 ( $\operatorname{lgG}_{2 a}$; Zymed, South San Francisco, CA, USA) and 2-4A5 (lgG ; Santa Cruz Biotechnology).

Statistical analysis. The statistical significance of the difference between assay groups was determined using the Student's $t$-test. $P$-values less than 0.01 were considered significant.

\section{Conflict of interest}

The authors declare no conflict of interest.

Acknowledgements. We thank Kyoko Tokunaga and Ikuko Suzu for secretarial and experimental assistance, respectively. This work was supported by a grant from Ministry of Education, Culture, Sports, Science and Technology of Japan (SS), and Health and Labor Sciences Research Grants from Ministry of Health, Labor and Welfare of Japan (SO).

1. Chitu V, Stanley ER. Colony-stimulating factor-1 in immunity and inflammation. Curr Opin Immunol 2006; 18: 39-48.

2. Hamilton JA. Colony-stimulating factors in inflammation and autoimmunity. Nat Rev Immunol 2008; 8: 533-544.

3. Sherr CJ. Colony-stimulating factor-1 receptor. Blood 1990; 75: 1-12.

4. Bourette RP, Rohrschneider LR. Early events in M-CSF receptor signaling. Growth Factors 2000; 17: 155-166.
5. Suzu S, Tanaka-Douzono M, Nomaguchi K, Yamada M, Hayasawa H, Kimura F et al. p56 $6^{\text {dok-2 }}$ as a cytokine-inducible inhibitor of cell proliferation and signal transduction. EMBO J 2000; 19: 5114-5122.

6. Yoshida H, Hayashi S, Kunisada T, Ogawa M, Nishikawa S, Okamura H et al. The murine mutation osteopetrosis is in the coding region of the macrophage colony stimulating factor gene. Nature 1990; 345: 442-444.

7. Wiktor-Jedrzejczak W, Bartocci A, Ferrante Jr AW, Ahmed-Ansari A, Sell KW, Pollard JW et al. Total absence of colony-stimulating factor 1 in the macrophage-deficient osteopetrotic (op/op) mouse. Proc Natl Acad Sci USA 1990; 87: 4828-4832.

8. Dai XM, Ryan GR, Hapel A, Dominguez MG, Russell RG, Kapp S et al. Targeted disruption of the mouse colony-stimulating factor 1 receptor gene results in osteopetrosis, mononuclear phagocyte deficiency, increased primitive progenitor cell frequencies, and reproductive defects. Blood 2002; 99: 111-120.

9. Lin H, Lee E, Hestir K, Leo C, Huang M, Bosch E et al. Discovery of a cytokine and its receptor by functional screening of the extracellular proteome. Science 2008; 320: 807-811.

10. Andrae J, Gallini R, Betsholtz C. Role of platelet-derived growth factors in physiology and medicine. Genes Dev 2008; 22: 1276-1312.

11. Hashimoto S, Suzuki T, Dong HY, Yamasaki N, Matsushima K. Serial analysis of gene expression in human monocytes and macrophages. Blood 1999; 94: 837-844.

12. Akagawa KS. Functional heterogeneity of colony-stimulating factor-induced human monocyte-derived macrophages. Int J Hematol 2002; 76: 27-34.

13. Verreck FA, de Boer T, Langenberg DM, Hoeve MA, Kramer M, Vaisberg E et al. Human IL-34-producing type 1 macrophages promotes but IL-10-producing type 2 macrophages subvert immunity to (myco)bacteria. Proc Natl Acad Sci USA 2004; 101: 4560-4565.

14. Fleetwood AJ, Lawrence $T$, Hamilton JA, Cook AD. Granulocyte-macrophage colony-stimulating factor (CSF) and macrophage CSF-dependent macrophage phenotypes display differences in cytokine profiles and transcription factor activities: implications for CSF blockade in inflammation. J Immunol 2007; 178: 5245-5252.

15. Suzu S, Kimura F, Ota J, Motoyoshi K, Itoh T, Mishima $Y$ et al. Biologic activity of proteoglycan macrophage colony-stimulating factor. J Immunol 1997; 159: 1860-1867.

16. Hiyoshi M, Suzu S, Yoshidomi Y, Hassan R, Harada H, Sakashita N et al. Interaction between Hck and HIV-1 Nef negatively regulates cell surface expression of M-CSF receptor. Blood 2008; 111: 243-250.

17. Conway JG, McDonald B, Parham J, Keith B, Rusnak DW, Shaw E et al. Inhibition of colony-stimulating-factor-1 signaling in vivo with the orally bioavailable cFms kinase inhibitor GW2580. Proc Natl Acad Sci USA 2005; 102: 16078-16083.

18. Rovida E, Lugli B, Barbetti V, Giuntoli S, Olivotto M, Dello Sbarba P. Focal adhesion kinase is redistributed to focal complexes and mediates cell spreading in macrophages in response to M-CSF. Biol Chem 2005; 386: 919-929.

19. Csar XF, Wilson NJ, McMahon KA, Marks DC, Beecroft TL, Ward AC et al. Proteomic analysis of macrophage differentiation. p46/52Shc tyrosine phosphorylation is required for CSF-1-mediated macrophage differentiation. J Biol Chem 2001; 276: 26211-26217.

20. Pandit J, Bohm A, Jancarik J, Halenbeck R, Koths K, Kim SH. Three-dimensional structure of dimeric human recombinant macrophage colony-stimulating factor. Science 1992; 258: 1358-1362.

21. Yamanishi K, Randawa ZI, Brown D, Masui Y, Yasuda S, Takahashi M et al. Structural analysis of recombinant human carboxy-terminal-truncated macrophage colonystimulating factor. J Biochem 1993; 113: 81-87.

22. Deng $P$, Wang YL, Pattengale PK, Rettenmier $C W$. The role of individual cysteine residues in the processing, structure, and function of human macrophage colony-stimulating factor. Biochem Biophys Res Commun 1996; 228: 557-566.

23. Savvides SN, Boone T, Karplus PA. Flt3 ligand structure and unexpected commonalities of helical bundles and cysteine knots. Nat Struct Biol 2000; 7: 486-491.

24. Suzu S, Harada H, Matsumoto T, Okada S. HIV-1 Nef interferes with M-CSF receptor signaling through Hck activation and inhibits M-CSF bioactivities. Blood 2005; 105 : 3230-3237.

25. Ashmun RA, Look AT, Roberts WM, Roussel MF, Seremetis S, Ohtsuka M et al. Monoclonal antibodies to the human CSF-1 receptor (c-fms proto-oncogene product) detect epitopes on normal mononuclear phagocytes and on human myeloid leukemic blast cells. Blood 1989; 73: 827-837.

26. Yang $X$, Chen $Y$, Gabuzda D. ERK MAP kinase links cytokine signals to activation of latent HIV-1 infection by stimulating a cooperative interaction of AP-1 and NK- $\kappa$ B. J Biol Chem 1999; 274: 27981-27988.

27. Burysek $L$, Syrovets $T$, Simmet $T$. The serine protease plasmin triggers expression of MCP-1 and CD40 in human primary monocytes via activation of p38 MAPK and janus kinase (JAK)/STAT signaling pathways. J Biol Chem 2002; 277: 33509-33517.

28. Tanimoto A, Murata Y, Wang KY, Tsutsui M, Kohno K, Sasaguri Y. Monocyte chemoattractant protein-1 expression is enhanced by granulocyte-macrophage colony-stimulating factor via Jak2-Stat5 signaling and inhibited by atorvastatin in human monocytic U937 cells. J Biol Chem 2008; 283: 4635-4651.

29. Mantovani A, Sica A, Sozzani S, Allavena P, Vecchi A, Locati M. The chemokine system in diverse forms of macrophage activation and polarization. Trends Immunol 2004; 25: 677-686.

30. Melgarejo E, Medina MA, Sanchez-Jimenez F, Urdiales JL. Monocyte chemoattractant protein-1: a key mediator in inflammatory processes. Int Biochem Cell Biol 2009; 41: 998-1001. 
31. Ohtsuka M, Roussel MF, Sherr CJ, Downing JR. Ligand-induced phosphorylation of the colony-stimulating factor 1 receptor can occur through an intermolecular reaction that triggers receptor down modulation. Mol Cell Biol 1990; 10: 1664-1671.

32. Thien $\mathrm{CB}$, Langdon WY. Negative regulation of PTK signalling by $\mathrm{Cbl}$ proteins. Growth Factors 2005; 23: 153-166.

33. Rubin $\mathrm{C}$, Gur G, Yarden Y. Negative regulation of receptor tyrosine kinases: unexpected links to $\mathrm{c}-\mathrm{Cbl}$ and receptor ubiquitylation. Cell Res 2005; 15: 66-71.

34. Lee PS, Wang Y, Dominguez MG, Yeung YG, Murphy MA, Bowtell DD et al. The Cbl protooncoprotein stimulates CSF-1 receptor multiubiquitination and endocytosis, and attenuates macrophage proliferation. EMBO J 1999; 18: 3616-3628.

35. Mancini A, Koch A, Wilms R, Tamura T. c-Cbl associates directly with the C-terminal tail of the receptor for the macrophage colony-stimulating factor, c-Fms, and down-modulates this receptor but not the viral oncogene v-Fms. J Biol Chem 2002; 277: 14635-14640.

36. Kallies A, Rosenbauer F, Scheller M, Knobeloch KP, Horak I. Accumulation of c-Cbl and rapid termination of colony-stimulating factor 1 receptor signaling in interferon consensus sequence binding protein-deficient bone marrow-derived macrophages. Blood 2002; 99: 3213-3219.

37. Joos H, Trouliaris S, Helftenbein G, Niemann H, Tamura T. Tyrosine phosphorylation of the juxtamembrane domain of the $\mathrm{v}-\mathrm{Fms}$ oncogene product is required for its association with a 55-kDa protein. J Biol Chem 1996; 271: 24476-24481.
38. Chen X, Liu H, Focia PJ, Shim AH, He X. Structure of macrophage colony stimulating factor bound to FMS: diverse signaling assemblies of class III receptor tyrosine kinases. Proc Natl Acad Sci USA 2008; 105: 18267-18272.

39. Martinez FO, Gordon S, Locati M, Mantovani A. Transcriptional profiling of the human monocyte-to-macrophage differentiation and polarization: new molecules and patterns of gene expression. J Immunol 2006; 177: 7303-7311.

40. Koyanagi Y, Miles S, Mitsuyasu RT, Merrill JE, Vinters HV, Chen IS. Dual infection of the central nervous system by AIDS viruses with distinct cellular tropisms. Science 1987; 236: 819-822.

41. Nakoinz I, Lee MT, Weaver JF, Ralph P. Differentiation of the IL-3-dependent NFS-60 cell line and adaptation to growth in macrophage colony-stimulating factor. J Immunol 1990; 145: 860-864.

42. Suzu S, Hiyoshi M, Yoshidomi Y, Harada H, Takeya M, Kimura F et al. M-CSF-mediated macrophage differentiation but not proliferation is correlated with increased and prolonged ERK activation. J Cell Physiol 2007; 212: 519-525.

43. Thompson JD, Higgins DG, Gibson TJ. CLUSTAL W: improving the sensitivity of progressive multiple sequence alignment through sequence weighting, positionspecific gap penalties and weight matrix choice. Nucleic Acids Res 1994; 22: $4673-4680$. 